\title{
The Role of Advance Composite material In Contemporary Buildings
}

${ }^{*}$ Ph.D. Candidate OBASANJO OWOYALE ADEOLA ${ }^{1}$ and Ph.D. Candidate MOHAMMED TAUHEED ALFA ${ }^{2}$

\author{
${ }^{1,2}$ Department of Architecture, Cyprus International University, Nicosia, Turkey \\ ${ }^{1}$ E mail:obasanjoadeolaowoyale@yahoo.com , ${ }^{2}$ E mail:mohammedtalfa@yahoo.com
}

\begin{tabular}{|l|}
\hline A R T I C L E I N F O: \\
\hline Article history: \\
Received 15 July 2018 \\
Accepted 23 September 2018 \\
Available online 13 October \\
2018 \\
\hline \\
Keywords: \\
Contemporary \\
Building, Composite \\
Material, \\
Straw Reinforced Clay \\
Bricks, \\
Building Construction
\end{tabular}

This work is licensed under a Creative Commons Attribution - NonCommercial - NoDerivs 4.0. "CC-BY-NC-ND"

\begin{abstract}
A B S T R A C T
Composite materials have been used from the earliest times, from wood, which is a naturally occurring composite of lignin and cellulose, through straw reinforced clay bricks to reinforced concrete. In the 20th century, a new breed of composite materials was developed using polymer matrices with high performance reinforcement fibres. The great effect and uncompromising properties of advance composite materials has enabled the emergence of composites cut across all fields of application and all areas or work, just to mention a few aeronautic engineering, automobile engineering, and medicine, military and building construction. Therefore, with emphasis on building construction, advance composite material has played a vital role in today's contemporary building construction method, by presenting its self as an alternative building construction material, its application has made the contemporary building construction much more flexible and achievable, compare to traditional building materials and its methods of construction. It further offers the building construction industry the technical know-how of having new possibilities of design styles, shapes and forms. Therefore, advance composite material proves it's self to be a better and a new alternative building construction material that remains construction friendly and flexible based on its properties. This study therefore tends to provide an overview on advance composite material, its application as well as its role in today's contemporary building.
\end{abstract}

JOURNAL OF CONTEMPORARY URBAN AFFAIRS (2018), 2(3), 95-101. https://doi.org/10.25034/ijcua.2018.4723

Www.ijcua.com

Copyright (c) 2018 Journal Of Contemporary Urban Affairs. All rights reserved.

\section{Introduction}

The human race has contributed tremendously to the improvement and processing of elementary building materials, they have become the reference point to mark the early stages of mankind discovery, invention and development, such as Stone Age, Bronze Age, Iron Age, etc. However the beginning of the recent hundred years positioned building materials to become more multifunctional and as well required the optimization of different properties. The evolution and concept of building materials has also been driven toward composite materials whereby two or more different material parts are being joined

\footnotetext{
*Corresponding Author:

Department of Architecture, Cyprus International

University, Nicosia, Turkey

E-mail address: obasanjoadeolaowoyale@yahoo.com
} 
together to provide a better combination of properties (Wegst et al. 2015). However, the rapid growth in technological development of the $21^{\text {st }}$ century played a great role in the emergence of advanced composite materials and its construction methods. It has also presented its self to be more dynamic, and as well made contemporary buildings to be more attractive and unimaginable, therefore based on some of the outstanding attributes advance composite material portray, the use and application of traditional building material and its construction method tends to decline with time in the nearest future (Karbhari, 1998). Advanced composite material has therefore presented its self with a much greater value and sustainability; the impact of these materials has also made contemporary buildings and their various design type embrace a much more dynamic and flexible system of construction.

Building Materials can be described as the embodiment of a building or a structure, and it production accounts for $30-50 \%$ consumption of raw materials worldwide (Tagnit-hamou and Soliman, 2018). The early discovery of building materials cannot be undermining rather it can be registered as one which has gone through a unique and extraordinary historic path of discovery, starting from the early civilization of the cave men who had to source material like wood, stones strands to create shelter that can stand as a form of protection from the harshness of the weather and harmful element of the environment of stay.

Ever since then man have never remained seldom in the search for possible innovative means to create materials that can go in hand with it environment, though the $19^{\text {th }}$ century remains a remarkable era that can be remembered for it industrialization and the expansion of modern construction tec hnological development which majorly had a great influence on building materials and its method of construction (Zabihi, 2010). Though the acceleration in advancement in technology of the past and much more innovative ideas today has lead in the creation of building materials that are gradually coming to the lam light. Today advance composite material can be regarded as one of the product of effective technological development of the $21^{\text {st }}$ century (Ljungberg, 2007). These innovative building materials tend to play a great role in contemporary buildings, in terms of environmental friendliness and sustainability and as well tend to bridge the gap between already existing traditional building materials.

\section{Materials and Methods}

This research employed the case study method for identifying various buildings across the world that have employed the instrumentality of environment friendly materials for construction and composition. The sources of the identified buildings are the internet and other archival materials which considers the use of sustainable construction materials for the purpose of their composition. A checklist was also prepared for the purpose of obtaining upto-date information about the selected buildings and also prepare a basic appraisal and evaluation criterial for the purpose of determining the extent of sustainability of the identified buildings.

\section{Discussions}

The awakening of 21 st century paved way to vast technological advancement. However, these technological advancements majorly cut across the construction industry, by influencing its building material types as well as its methods of construction. This advancement further brought about a dynamic change in the building industry, by therefore producing innovative building materials (advance composite material) that offer unique properties as well as wide variety of functions, and structural performance qualities that are sustainable and environmentally friendly, and are as well very much impossible to archive with normal traditional building materials (Akadiri et al., 2012)

in terms of it:

- New aesthetic possibilities and ability to mould complex fluid and create design of different forms, shapes and styles

- Being able to Provide special integrated surface finishes and effects

- Being able to provide significant savings in weight usually up to $15 \%$

- Being able to ensure superior durability with degradation through life

- Being able to provide Rapid installation and cost on site

- Being able to Unlock the possibilities of architectural design

- To ensure Temperature and chemical resistance

- To ensure Flex performance

- To ensure Dimensional stability.

With the above mentioned qualities, architect, designers and engineers tend to play a vital role with the use and application of 
contemporary building material. They are therefore exposed with the challenges of new idea, as well as new knowledge and understanding of the nature of these new material, such as their physical and chemical properties, their structural properties, their characteristics in fire, their interaction with other material as well as their anticipated durability for any given situation, cost maintenance requirement and potential for recycling and other environmental issues such as embodied energy. However, it also further relates to it impact in terms of health and safety, as well as its multiplicity towards aesthetic properties.

Advance composite materials as a contemporary material are mixture of two or more materials to form a composite material. It is classified as an advance composite, because they are determined by unusually high strength fibers with high stiffness or modulus of elasticity characteristic compare to other materials or composite, such as fiberglass and concrete. Advanced composite systems are divided into two basic types, thermosets and thermoplastics. Thermosets are by far the predominant type of composite in use today while Thermosets are subdivided into several resin systems including epoxies, phenolic, polyurethanes, and polyimides. These, epoxy systems currently dominate the advanced composite industry today.

The first inception of advanced composite materials can be traced back to the past 50 years with a wide range of demanding applications. However, one of its very first commercial application was noted shortly after the Second World War, with a USA Company named Mine Hunters, which introduced advanced composites into military vehicles, as well as opened doors to the multiplicity of a much more advanced composite material that are now applicable in different forms and functions in today's modern world. Advanced composite materials are now the common material for high performance super yachts, large wind turbine blades, modern aircraft, and sports and leisure equipment including ski's, snowboards and surfboards. However, they are also being widely used in construction, because they tend to offer significant weight savings and their ability to form complex shape, give architects greater freedom in design. (Nguyen, Mendis, Ngo, Tran, \& Nguyen, 2013), noted that the applications of advance composite material has witnessed and reflected a great shift in the construction industry through series of research and project carried out since the 1990s. However, its market share distribution has risen more than 25\%, therefore projecting the construction industry as the second largest field in the application of advance composite, See Fig. 1.

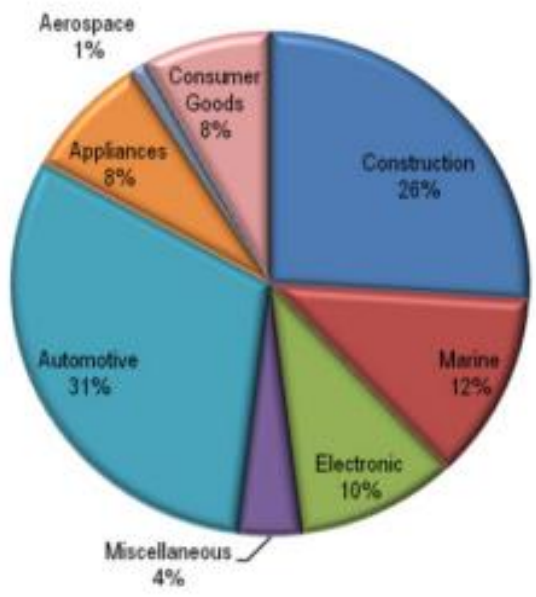

Fig.1: Shows a chart showing the differential scale in the application advance composite material (Nguyen, Mendis, Ngo, Tran, \& Nguyen, 2013)

An example of such is exhibited in Heydar Aliyev Center designed by Zaha Hadid Architects. The building which is a contemporary building characterized with a complex geometry, it also represent a wide contrast from traditional building materials, because some of it major construction material used were advance composite material in form of Glass Fibre Reinforced Concrete (GFRC) and Glass Fibre Reinforced Polyester (GFRP), they were chosen as ideal cladding materials, because they allow for powerful plasticity in building design while responding to very different functional demands related to a variety of situations, see Fig 2

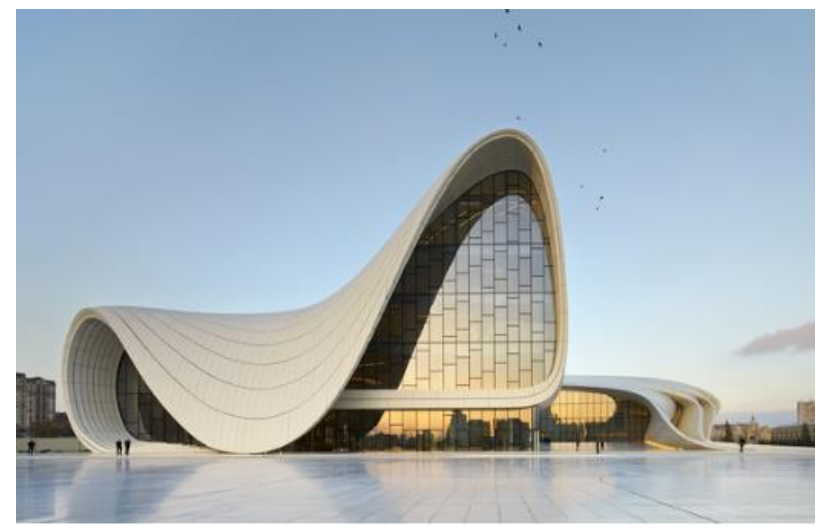

Fig.2: The representation of Heydar Aliyev Center Azaebarjan designed with advance composite material. Designing with advance composite materials opens up a wide range of design possibilities, it can also optimize the performance of a structure by the modification of the building blocks of the materials. The chemistry of the 
resins can as well be modified to produce materials with specific characteristics for specified use.

\subsection{Characteristics of advance composite material}

(Nguyen, Mendis, Ngo, Tran, \& Nguyen, 2013), described Advance Composite materials, to possess high advantages in strength, stiffness, low density, as well as manufacturing flexibility; therefore, their potential in replacing traditional building materials (such as concrete, aluminum and steel) in building construction has become attractive. Advance composite materials are not only limited to building material alone, rather their use and application also have a broad and proven application in design flexibility as well as dramatic shapes, styles and forms in architectural aesthetics, interior finishes and landscaping design etc. one of The biggest characteristics of modern day advance composite materials are the fact that they are light in nature but also very strong to stand the taste of time. They are also innovatively driven by the choice or specification of an appropriate combination of matrix and reinforcement materials. It can therefore be made to exactly meet the specified requirements of any particular application. However, based on its outstanding attribute, advance composite materials tend to plays a vital role in taking construction, design, aesthetic and remodeling forward in this contemporary era. Therefore, with recent technological advancement, advance composite materials are now designed to respond with various stimuli which are changed significantly into predictable manner in response to the environment.

\subsection{Aesthetics possibilities with advance composite material}

Aesthetic problem due to complexity in design and architectonics has been notable in the construction industry, as a result of the low level of technology involved in traditional building material and its method of construction. Architects, designers and engineers show great interest in the use of advance composite materials in the formation and composition of contemporary buildings, to advance composite material for the ability to allow cost effective realization of unique shapes, styles and forms as well as flexible aesthetics, while accommodating architectural designs and needs. The long-term durability, weathering resistance, and the exceptional mechanical properties have recently suggested the adoption of advance composite material for building façade systems in an increasing number of buildings worldwide (Berardi \& Dembsey, 2015).

However contemporary buildings and structures built from advance composite materials has revealed and proven its flexibility by allowing all forms, shape and style of aesthetics to be achievable with high durability and tensile strength. Nonetheless Designs with advance composite materials are easily archived in time and safety. Advance composite materials are innovative candidates to be used in contemporary building façade and aesthetic systems because they offer excellent performance and cost effectiveness in aesthetic and complex designs.

With the benefits of high strength and stiffness, low density, and highly flexible shaping, advance composite material become potential candidates in the replace of traditional building materials (such as aluminum and steel) in civil applications. For example, advance composite materials contribute up to $50-70 \%$ weight reduction as an alternative to traditional metal-based materials. In addition, the manufacturing flexibility of advance composite material products is well-suited with the demands of architects and engineers in designing complex building structures such as the façade systems while maintaining mechanical properties and durability. Therefore, it can be noted that one of the major roles advanced composite material play in contemporary buildings are the possibility of new aesthetic. However this can be considerably high due to the vast use of advance composite materials in the twenty-first century buildings and structures. Since the introduction of advance composite material in buildings, it has paved way for some many fabricators to produce composite materials from recycled and renewable materials in other to create building elements for buildings facades and the general aesthetics of buildings and its environment.

Composite materials, such as Glass fiber reinforced polymers (GFRPs), carbon fiber reinforce polymers (CFRPs), possess the advantages of high strength, stiffness, low density, and flexibility; therefore, their potential in replacing traditional materials (such as concrete, aluminum and wood) in building aesthetics and facade has become an interesting and attractive one in the building industry today. See below Fig.3, Fig.4 and Fig.5

- The use of sandwich Glass fiber and epoxy resin combine with a lightweight 
foam core that is use for the finishing of the facade of the Harman High speed Rail station in Medina.
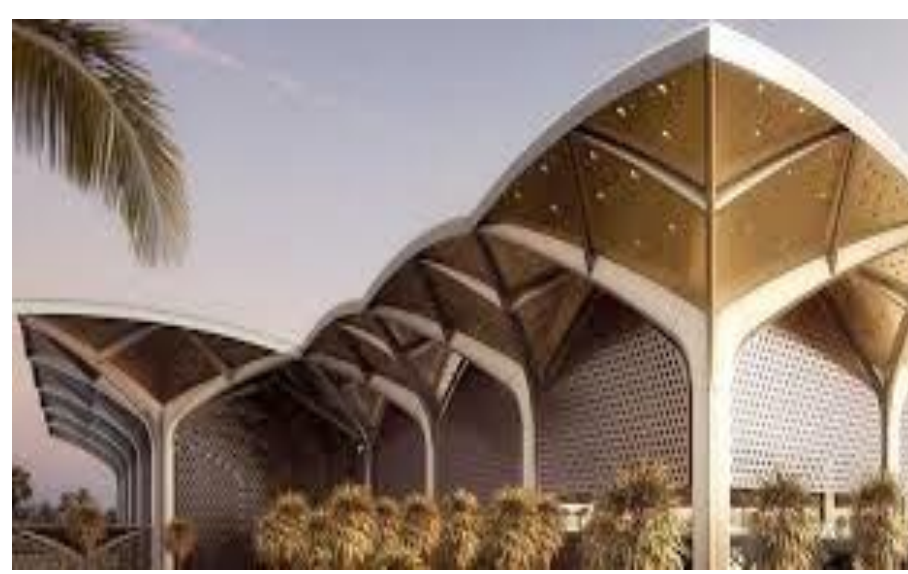

Fig.3: The representation of the Haramain high-speed rail station. (www.burohappold.com.)

- The use of Glass fiber reinforces concrete columns of greater surface finishing and aesthetic compare to concrete and more timeserving in construction.

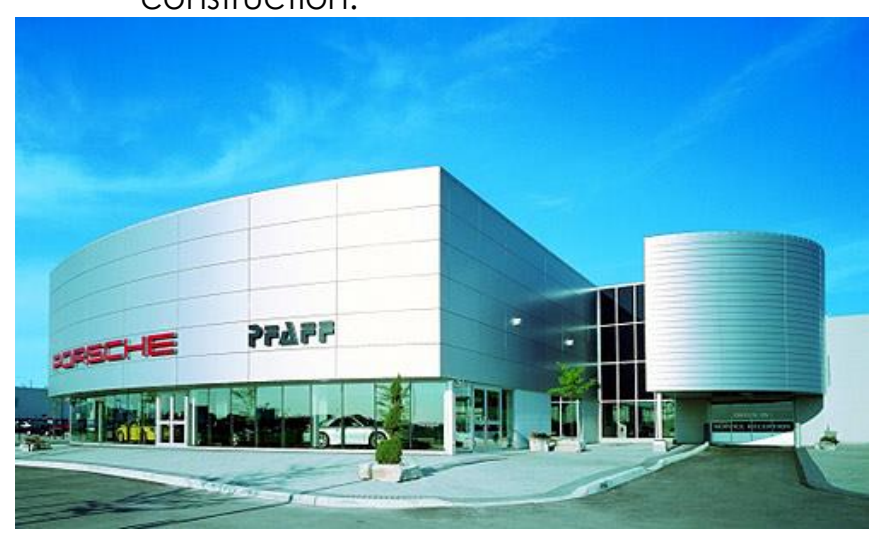

Fig.4: Show the representation of columns constructed with composite of glass and steel. (www.strombergarchitectural.com)

- The use of Glass fiber reinforced polymer to create the design of a museum with great surface finishing, and a façade of free flow of form without column support.

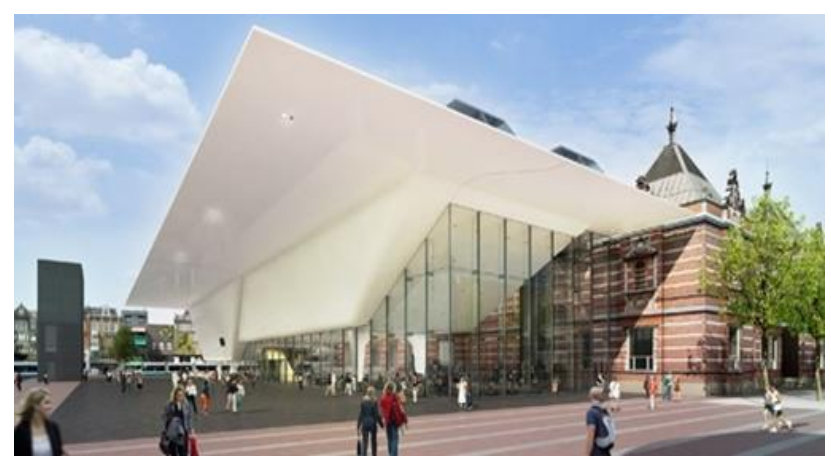

Fig.5: Illustrate the aesthetic possibility of FRP on the city museum façade with free flow of form without column supports.

\subsection{The influence of advanced composite material in existing buildings and structures}

Advance Composites materials are one of the most widely used materials today, because of their innovative and sustainable adaptability to different environmental and structural condition. It also allows for the combination with other materials, so as to serve specific purposes and exhibit desirable properties in existing buildings and structure. Therefore, it uses and application in buildings and structures they are selected carefully based on it intênded required purpose for the repair of adimaged elements in buildings or structural elements, so as to help prevent futuristic occurrence of failure of any kind in the long run use of the building or structure. However, the use and application of advance composite materials in existing buildings are to enable performance quality, structural stability and a functional structure that can stand the taste of time.

Advanced composite material like fibre reinforced polymer are proven technology used for upgrading and strengthening of concrete, masonry, timber as well as steel structure. Generally advance composite materials have exceptionally high strength, yet they remain very light and easy to work with. it application has cut across all areas of construction ranging from increase in capacity of existing buildings, bridges, seismically upgrading structure, correcting design or construction error and allowing for further modification or change in use. Fig. 6 \& 7 shows below some of the application of fibre reinforced polymer and some of it advantages

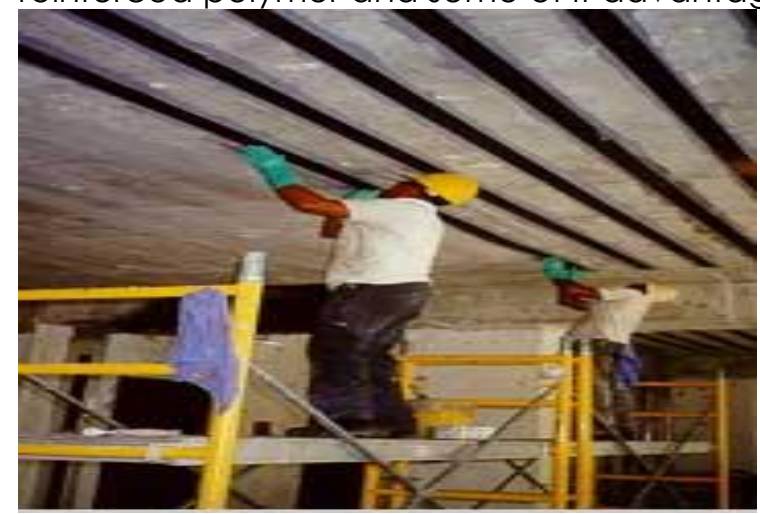

Fig. 6: shows repair of concrete beams with ACM. 


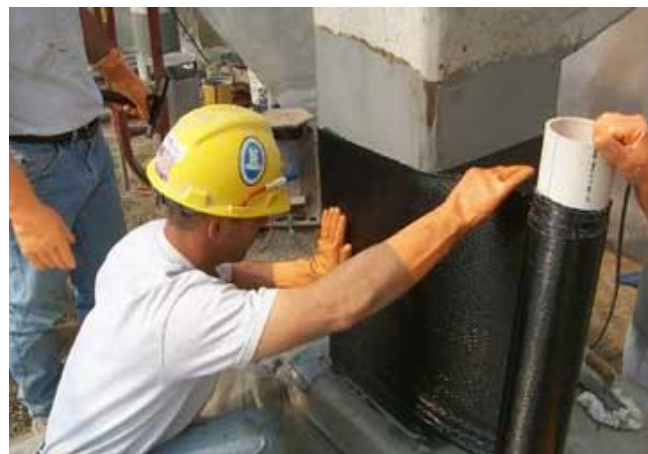

Fig. 7: shows the repair of concrete column with ACM.

Some of the advantages of fibre reinforced composite are:

- Economy and durability

- Ease of application

- Extremely high tensile strength

- Outstanding fatigue behavior

- Absolute resistance to corrosion

- Ability to upgrade structure while in use

- upgrade possibilities even with limited access

A rhetorical studies conducted by (T. Keller, 2001) has proven that Fibre-reinforced polymers (FRP) have found increased application in bridge and building construction in recent years. This is predominantly due to the advantageous properties of these materials, such as low self-weight, high strength, free formability and substantial resistance to corrosion and fatigue. Chiewanichakorn \& Toranzo, (2011), also pointed out that a comprehensive study on Seismic retrofitting of st. Joseph Hospital revealed the use and application of advanced composite materials for the enhancement of column, slab, wall and beam elements. It also further depict the practical use and application of advance composite material in archiving certain structural standards as assigned by the united states government, see below fig.8, fig.9.

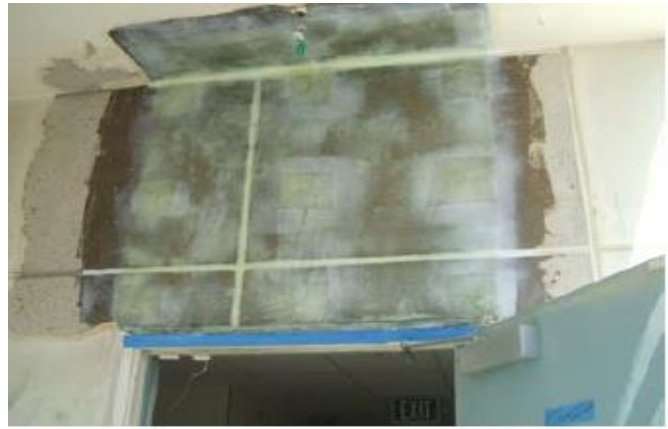

Fig.7: depict the use of advance composite in the healing of concrete spall on wall (Chiewanichakorn \& Toranzo, 20111 .
The application of advance composite material enabled protection against concrete spalling and as well as reduced the possibility of body injury. Basically the use of advanced composite material can contain any form of damage to the concrete that could occur during a seismic event.

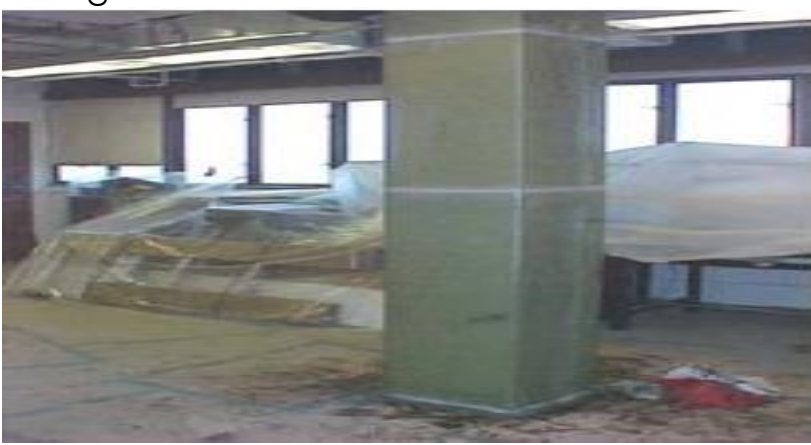

Fig.8: Depict the use of advance composite in the healing of concrete spall on wall (Chiewanichakorn \& Toranzo, 2011).

Columns are retrofitted with advance composite material. Advance composite wraps are applied in circular direction to supplement the transverse steel reinforcement and to as well increase the shear capacity of the columns and to provide plastic hinge confinement.

\subsection{Advanced composite material as an innovative and sustainable building material for the feature}

Advance composite materials are currently revolutionizing architecture and design. Their applications in the field of construction have allowed the progressive replacement of traditional materials and many barriers that designers used to find when implementing projects with a futuristic design have disappeared. Up until now, advance composite materials have been more commonly used in repairs, secondary structures and huge self-supporting structures, such as domes. However, it's innovative drive open door for architects and engineers to develop more complex works which will satisfy the creativity of some designers and architects. It also offers the desire to challenge the established certain canons when designing buildings and unique works, These which are only possible with composite materials, since we take advantage of the combination of the low weight of these materials and their ability to be molded in such complex shapes (Isabel\&Soler, 2016). 


\section{Conclusion}

The emergence of composite materials in the building industry came as a result of certain limitation and factors over traditional building material. However based on the versatility of advance composite materials, a wide range of construction development has been achieved ever since its inception in to the building industry. The use and application of Advance composite material enables broad and proven application in contemporary building, it flexibility in design also enables great achievement in complex geometric shapes, styles, and forms as well as a much more flexible method of construction

Design complexity can been resolved with the ability of advance composites materials. However it further plays a very unique role in the repairing of existing buildings and structure due to its unique characteristics over traditional building materials with high flexibility characteristics. There is a great possibility of achieving new aesthetics in construction and in repair of old buildings.

Advance composite materials tend to offers a very wide range of applications, properties and advantages in present day building technology which are far impossible with traditional building materials such as new aesthetic possibilities, abilities to mould complex fluid and creative form which integrate special surface finishes and effect, significant saving in weight usually up to $15 \%$, superior durability with degradation through life cost on site and less degradation, flex performance, dimensional stability, rapid installation as well as unlocking the possibilities of architectural design. Therefore,

composite material can be assessed as a new intervention in the modern day building industry with so many credits against traditional building material.

\section{Acknowledgement}

This research did not receive any specific grant from funding agencies in the public, commercial, or not-for-profit sectors.

\section{References}

Akadiri, P. O., Chinyio, E. A., \& Olomolaiye, P. O. (2012). Design of a sustainable building: A conceptual framework for implementing sustainability in the building sector. Buildings, 2(2), 126-152. https://doi.org/10.3390/buildings2020126

Berardi, U., \& Dembsey, N. (2015). Thermal and Fire Characteristics of FRP Composites for Architectural Applications. Polymers,
7(11)

2276-2289.

https://doi.org/10.3390/polym7111513

Carney, P., \& Myers, J. J. (2003). Shear and Flexural Strengthening of Masonry Infill Walls with FRP for Extreme Out-of-Plane Loading. Architectural Engineering 2003. https://doi.org/10.1061/40699(2003)45

Chiewanichakorn, M., \& Toranzo, L. (2011). Seismic Retrofit of St. Joseph Hospital Using Advanced Composite Materials for the Enhancement of Column, Slab, Wall and Beam Elements. Retrieved from:

https://www.google.com.cy/\#q=Seismic +Re trofit+of+St.+Joseph+Hospital+Using+Advanc ed+Composite+Materials+for+the+Enhance ment+of+Column\%2C+Slab\%2C+Wall+and+ Beam+Elements

Karbhari, V. M. (1998). Use of composite materials in civil infrastructure in Japan. WTEC report. International Technology Research Institute, World Technology (WTEC) Division. Available at: http://www.wtec.org/loyola/pdf/compce.p df

Ljungberg, L. Y. (2007). Materials selection and design for development of sustainable products. Materials \& Design, 28(2), 466-479. https://doi.org/10.1016/j.matdes.2005.09.006

Nguyen, Q., Mendis, P., Ngo, T., Tran, P., \& Nguyen, C. (2013). Innovative materials for next generation façade systems. From Materials to Structures: Advancement through Innovation, 729-734. https://doi.org/10.1201/b15320-129

Tagnit-hamou, A., \& Soliman, N. (2018). U.S. Patent No. 9,856,171. Washington, DC: U.S. Patent and Trademark Office.

Wegst, U. G., Bai, H., Saiz, E., Tomsia, A. P., \& Ritchie, R. O. (2015). Bioinspired structural materials. Nature materials, 14(1), 23. https://doi.org/10.1038/nmat4089

Zabihi, S. (2010). Evaluating the Effects of Modern Movement on Contemporary Residential Buildings in Iran's Capital CityTehran (Doctoral dissertation, Eastern Mediterranean University (EMU)). Available at: http://irep.emu.edu.tr:8080/xmlui/handle/11129/13 1 